\title{
Duplex Stainless Steel of Type UNS S32101 and Ferritic Stainless Steel of Type AISI 430 Subjected To Cathodic Hydrogenation
}

\author{
${ }^{1,4}$ A.M. C. Oliveira, ${ }^{1}$ R.C. Paredes, ${ }^{2}$ W.C. Godoi, ${ }^{3}$ A.P. Vaz \\ ${ }^{1}$ Federal University of Paraná, Polytechnic Center, Curitiba, Brazil \\ ${ }^{2}$ Federal Technological University of Paraná - Department of Physics \\ ${ }^{3}$ Lapa Education College, Lapa, Paraná, Brazil \\ ${ }^{4}$ Faculty Estacio of Curitiba, Paraná, Brazil
}

\begin{abstract}
This work presents a study on the duplex stainless steel UNS S32101 and ferritic AISI 430 when subjected to cathodic hydrogenation, to ascertain their behavior under the action of hydrogen. Throughout the research, with the aid of optical (MO), scanning electronics (SEM) and atomic force (AFM) microscopy, both hydrogen embrittlement and pitting corrosion after hydrogenation and degassing in UNS S32101 duplex stainless steel became evident. Subsequently, the X-ray diffraction performed to verify the phase transformations confirmed the transformation of the austenitic phase into the martensitic phase in the duplex steel and confirmed the formation of $\mathrm{Cr} 23 \mathrm{C} 6$ precipitates in the ferritic steel. And so, it corroborated with the SEM images, proving the transformation of $\sigma$-phase agent of pitting corrosion in duplex steel.
\end{abstract}

Keywords: Hydrogen Embrittlement, Duplex Stainless Steel, Ferritic Stainless Steel, Phase Transformation, Precipitates, Corrosion.

\section{Introduction}

Due to the rise in nickel prices, since 1990, duplex stainless steels are extensively researched, as explained by Mei and Guimarães [1], Verma et al [2] and Manova and Mändl [3]. Such steels have a favorable combination of the properties of both austenitic and ferritic stainless steels, that is, they have high mechanical strength, good toughness, very good resistance to corrosion in various means and excellent resistance to fatigue and corrosion under stress.

However, hydrogen has a unique ability to penetrate several solid metals directly, due to its "ordinary" gaseous state, when this metal is in a susceptible state.

In such a way, the use of materials, without processing the transformation of oil into its derivatives is of concern, since the exposure to hydrogen is high. So knowing the behavior of these steels is of paramount importance. It is noteworthy that the hydrogen penetration ability is improved by ionization or by the dissociation of atoms, in this way the hydrogen is able to penetrate materials that were previously impenetrable. Thus, due to the great risk of catastrophic failures caused by hydrogen, the appropriate choice of material to work in hydrogenated environments must be very careful, in order to know its mechanicalmetallurgical behavior in these environments rich in hydrogen. Since, depending on the material, hydrogen transforms the phase, as well as causing the embrittlement in the form of an intense surface cracking. Once, microstructural analyzes show that; according to Gavriljuk et al [4], Yang et al [5] and Carter and Cornish [6]; hydrogen induces phase transformations, that is, austenite becomes unstable giving rise to two martensitic phases, one called $\square$ phase, and another called denomin $\alpha$ 'phase. Thus, hydrogen induces the appearance of delayed fracture, as a consequence of the appearance of numerous surface cracks, which occur during degassing at room temperature, according to Matsuoka, Yamabe and Matsunaga [7], Rao et al [8] and Hardie , Charles and Lopez [9]. Therefore, studies of materials and surface treatments are constant to prevent the entry of hydrogen into the material in use. 


\section{Experimental Procedure}

For broad understanding, duplex and ferritic stainless steels were machined to a smooth surface. Then, with a cutting disc, $1.0 \mathrm{~cm} 2$ samples were cut, then the samples were embedded, mechanically sanded in paper sandpaper (with $220 \square \mathrm{m}$ and $1200 \square \mathrm{m}$ grain sizes), polished with felt cloth and aluminum alumina. granulometry $0.30 \square \mathrm{m}$, in the sequence neoprene cloth and $0.1 \mu \mathrm{m}$ colloidal silica, to guarantee (smooth) surfaces that can be analyzed through optical microscopy, electron microscopy and X-ray diffraction. After polishing, samples of duplex steel were subjected to cathodic hydrogenation for four hours at a temperature of $30^{\circ} \mathrm{C}$ and those of ferritic steel were also subjected to cathodic hydrogenation, but for less time - 30 minutes - at a temperature of $30^{\circ} \mathrm{C}$, since this type of steel is more susceptible to the harmful effects of hydrogen.

The solution was prepared as follows: dilution of $1 \mathrm{~g}$ of As2O3 in $1 \mathrm{~L}$ of distilled water at $80{ }^{\circ} \mathrm{C}$. The hydrogenation solution: consisted of diluting $100 \mathrm{ml}$ of the arsenic trioxide solution in a $0.5 \mathrm{~mol} \mathrm{L-1}$ solution of $\mathrm{H} 2 \mathrm{SO} 4.27 \mathrm{ml}$ of $\mathrm{H} 2 \mathrm{SO} 4$ was applied in 1 liter of solution. In this solution, arsenic trioxide was applied to avoid the loss of hydrogen to the atmosphere. A platinum anode and a current density of 1000 $\mathrm{A} / \mathrm{m} 2$ were used. Figure 1 shows a representative diagram of the hydrogenation process.

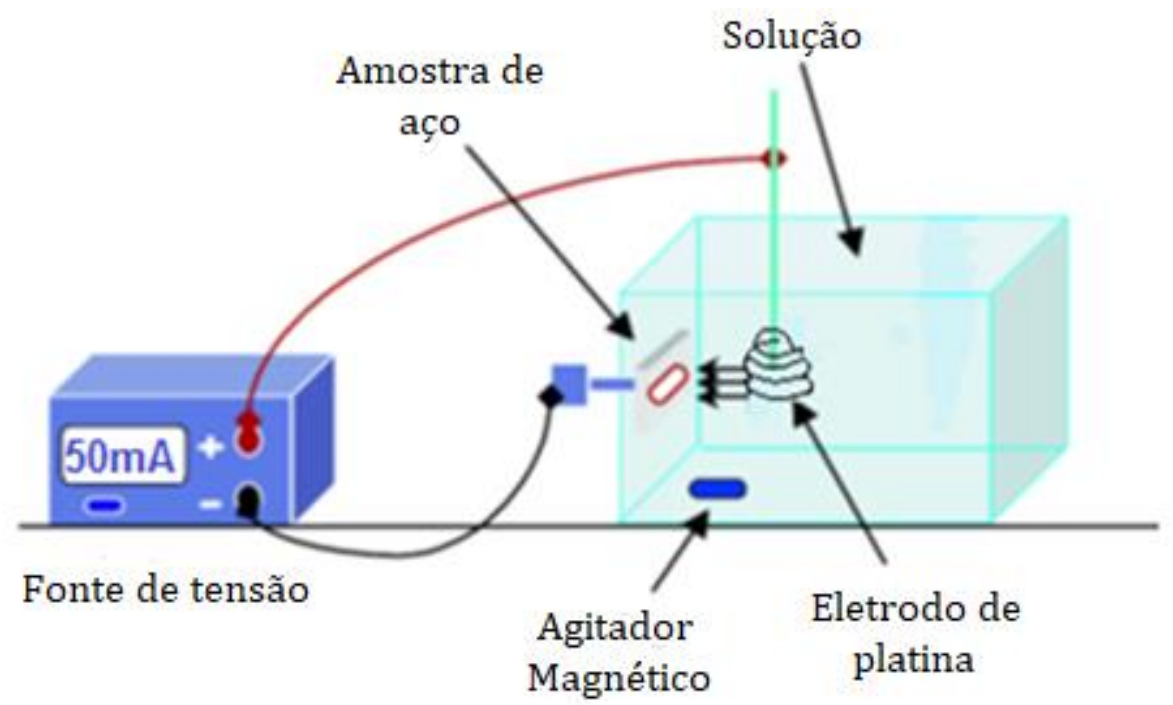

Figure 1: Schematic of the hydrogenation process. Source: The author.

The samples were kept at room temperature after the hydrogenation was interrupted to degass and subsequently observed for damage caused by hydrogen. The damage caused by optical, electronic and atomic force microscopy was evaluated, as well as analyzed by X-ray diffraction.

\section{Results and discussions}

In order to verify the microcracks, generated in the degassing process after cathodic hydrogenation, optical microscopy $(\mathrm{OM})$ images were sought. Because this hydrogen embrittlement in this type of steel was expected, especially in austenitic grains, as, as already discussed in other works, there is an intense surface cracking of austenitic stainless steel after hydrogenation [10-13].

Figures 2 and 3 are optical micrographs of the UNS S32101 duplex stainless steel. Figure 2 of this steel is only sanded, polished and attacked (Murakami) to reveal the ferritic ( $\square$ ) and austenitic $(\square)$ grains. Figure 3 is of the UNS S32101 duplex stainless steel sanded, polished, hydrogenated for 4 hours and degassed for a week. 


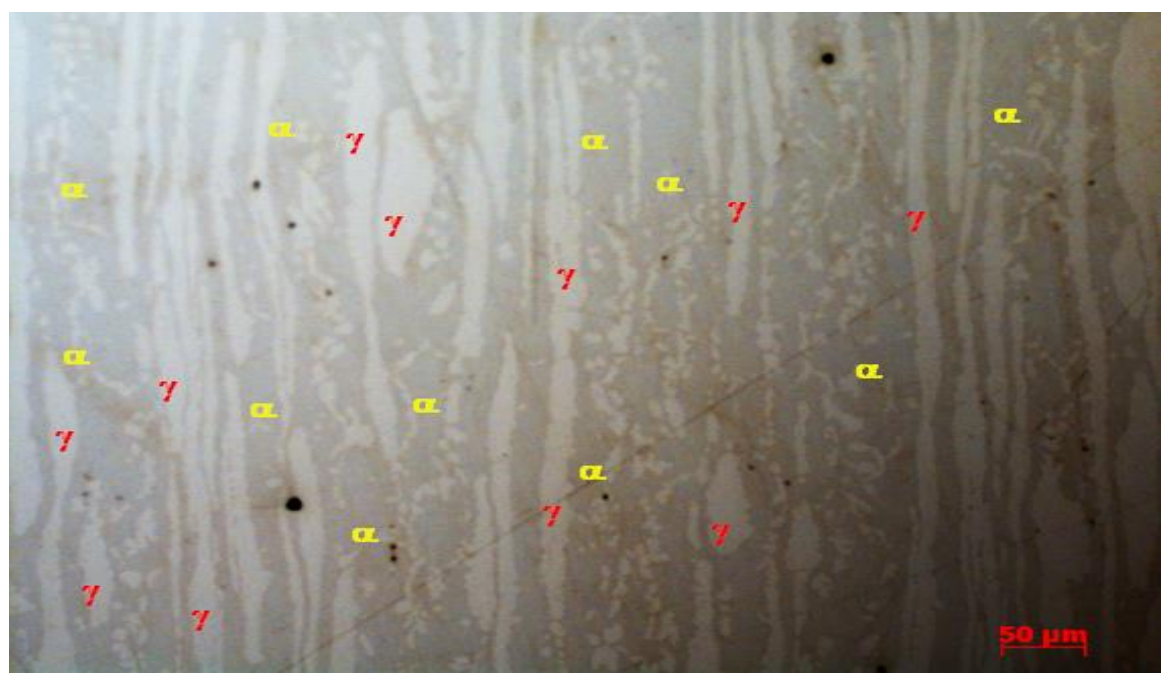

Figure 2: optical microscopy image of sanded, polished UNS S32101 duplex stainless steel, with Murakami attack to reveal austenitic ( $\square$ ) and ferritic ( $\square$ ) grains, with 200x magnification.

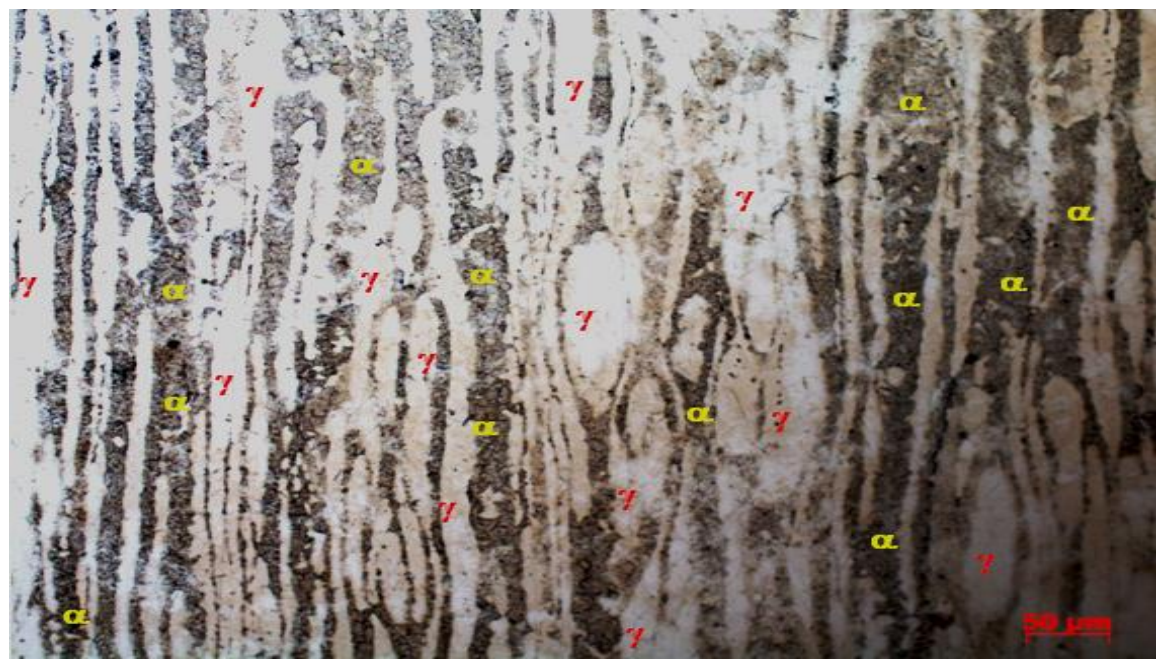

Figure 3: optical microscopy image of UNS S32101 duplex stainless steel sanded, polished, hydrogenated for 4 h and degassed for 7 days, with a 200x magnification.

In figure 3 the difference was noted, as the ferritic grains appear darker, showing the damage caused by the entry and exit of hydrogen in the steel.In order to know an explanation capable of elucidating the destruction caused by hydrogen in the ferritic grains, the samples of the ferritic stainless steel AISI 430 were hydrogenated and analyzed. Figure 4 is an optical microscopy image of 430 ferritic stainless steel just sanded and polished. Figure 5 is an optical microscopy of ferritic stainless steel 430 after hydrogenation for $30 \mathrm{~min}$ and degassing for one week. In this it is possible to see that the surface was damaged after the insertion and disinsertion of the hydrogen. Note the appearance of innumerable cavities, as if the hydrogen transformed the ferrite into precipitates and those on the surface were detached, showing only the cavity at the site. 


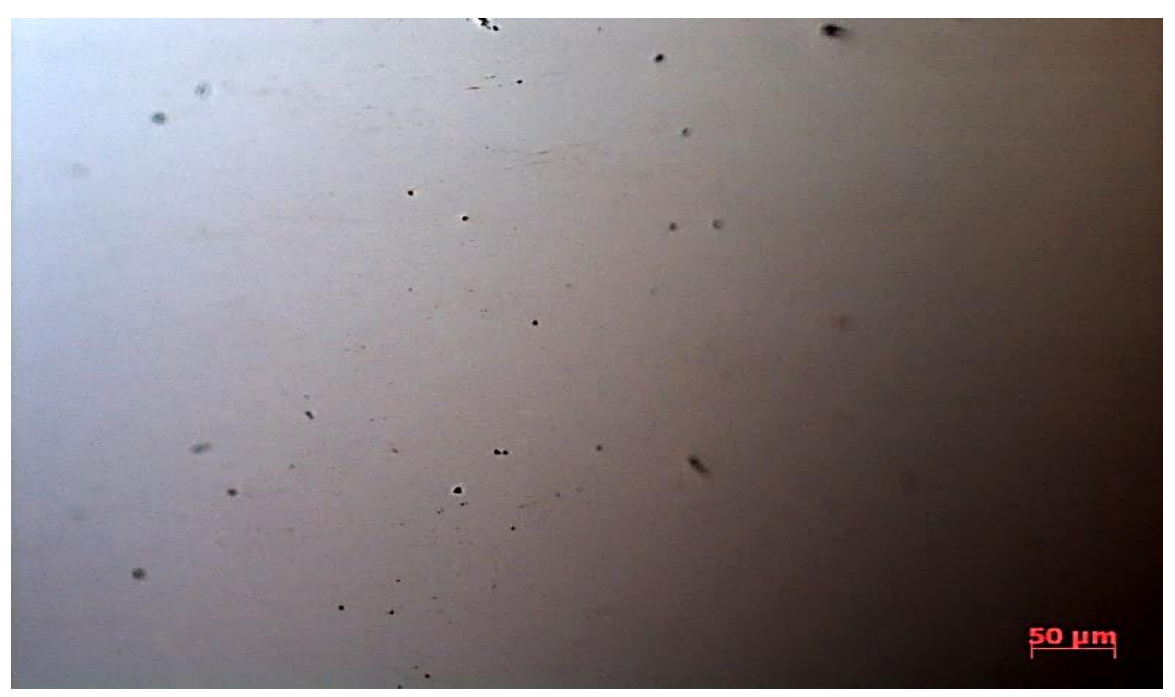

Figure 4: optical microscopy image of sanded and polished AISI 430 ferritic stainless steel, with a $200 x$ magnification.

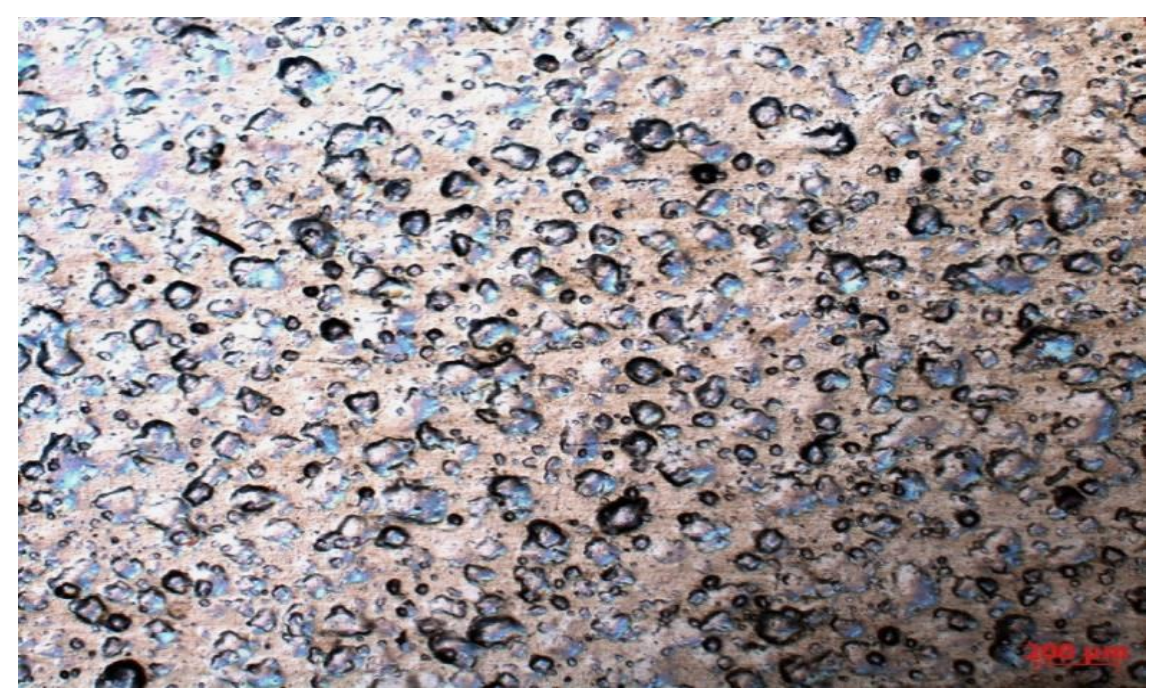

Figure 5: optical microscopy image of sanded, polished, polished, hydrogenated AISI 430 stainless steel for 30 min and degassed for 7 days, with a 200x magnification.

Due to the limitations of optical microscopy, scanning electron microscopy images were sought to better clarify the damage caused by the entry and exit of hydrogen from the material. Thus, figures 6 and 7 are SEM images of duplex stainless steel of the type UNS S32101 hydrogenated for 4h and degassed for a week. With greater/magnifications, as in the micrographs shown in figures 6 and 7, the microcracks in the austenitic and ferritic grains became evident, in addition to localized corrosion, in the form of pitting corrosion in the ferritic grains. Since, this corrosion is characterized by pits that are formed in the material, and these normally penetrate the interior of the metal from the surface. This type of corrosion is common to go unnoticed, because very often, it is not detected until the failure occurs. Figures 8 and 9 are SEM images of ferritic stainless steel of the AISI 430 type. In figure 8, with a 300x magnification, there are some cracks inside the cavities left at the outlet of the hydrogen. Figure 9 is an enlargement - $1500 \mathrm{x}$ - of this area, making it possible to observe that they are really cracks within the cavity. In this way, it is demonstrated that there is the formation of precipitates and that the hydrogen that is below these precipitates to leave the metal, pushes them, detaching them from the material and thus, not only leaving a cavity, but also cracks within them. 


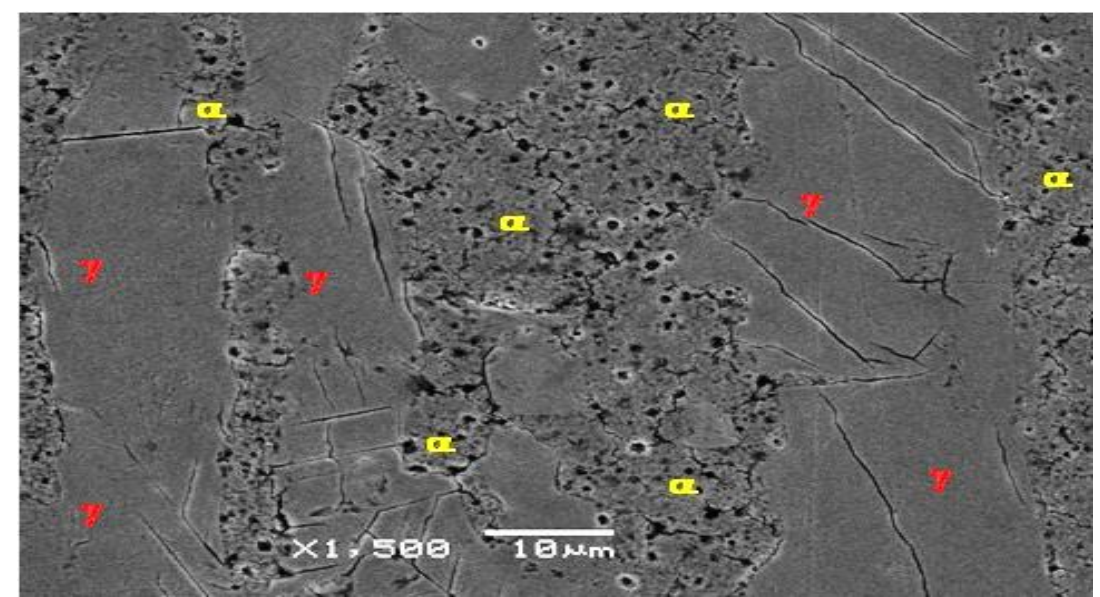

Figure 6: Scanning electron microscopy image of UNS S32101 duplex stainless steel sanded, polished, hydrogenated for 4 hours and degassed for 7 days, with a 1500x magnification.

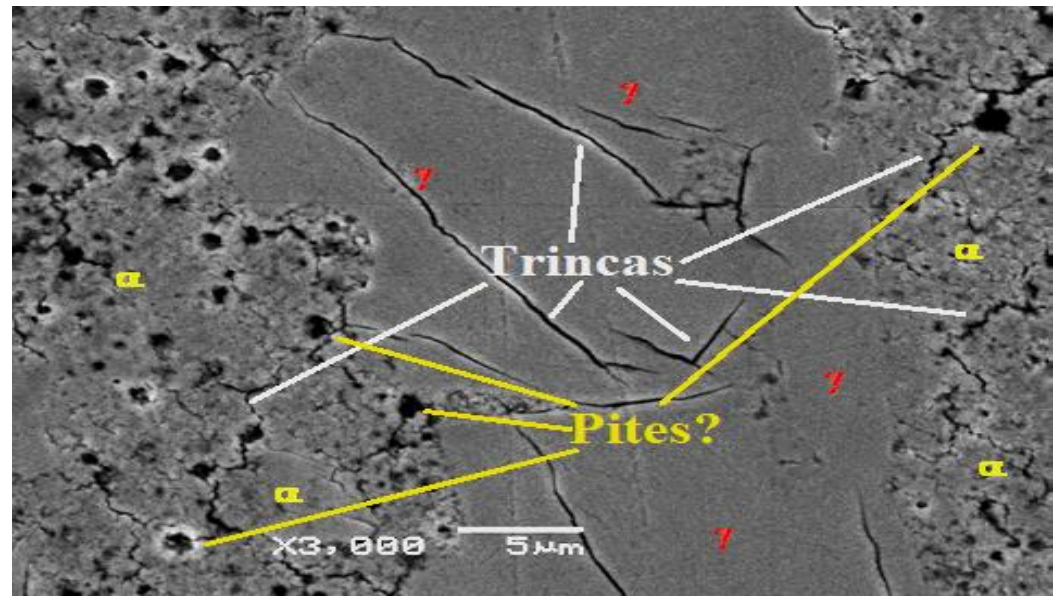

Figure 7: scanning electron microscopy image of UNS S32101 duplex stainless steel sanded, polished, hydrogenated for 4 hours and degassed for 7 days, with a 3000x magnification.

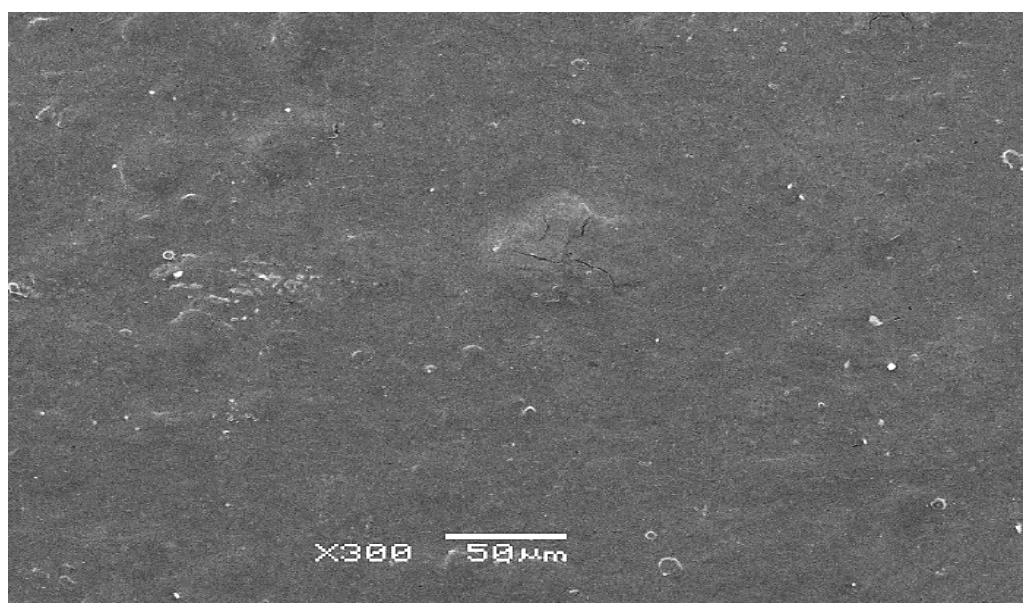

Figure 8: scanning electron microscopy image of sanded, polished, polished, hydrogenated AISI 430 ferritic stainless steel for 30 min and degassed for 7 days, with a 300x magnification. 


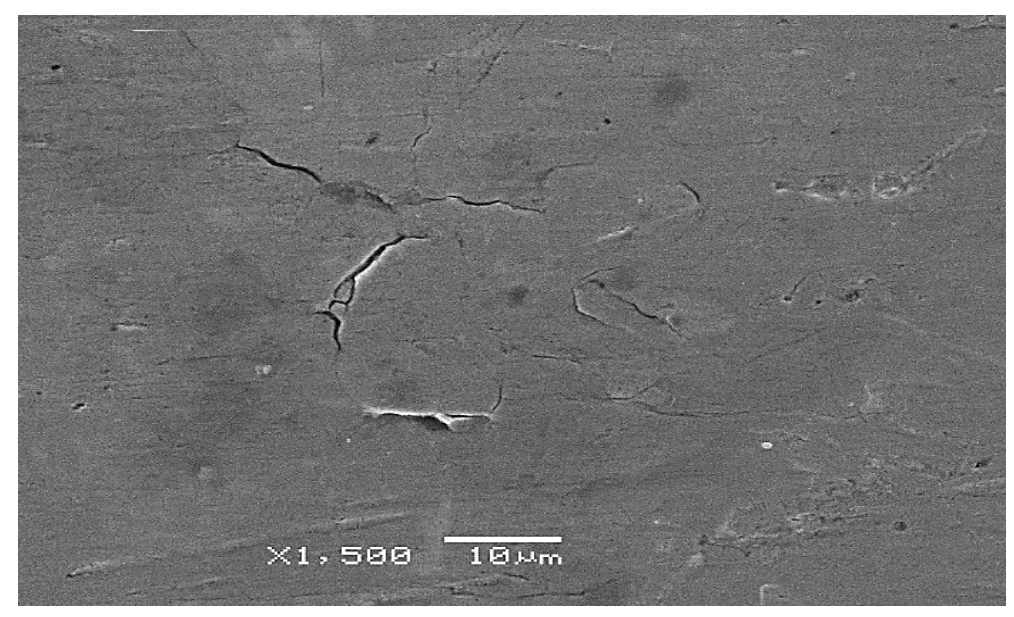

Figure 9: scanning electron microscopy image of sanded, polished, polished, hydrogenated AISI 430 ferritic stainless steel for 30 min and degassed for 7 days, with a 300x magnification.

The atomic force microscopy technique was used to verify the depth of cracks and pits that were generated after hydrogenation in the UNS S32101 duplex stainless steel. Figure 10 shows the atomic force microscopy image of UNS S32101 duplex stainless steel without hydrogenation, only polished. In this, it is possible to observe that the variation of the superficial relief is around 19 nanometers for the deepest regions. Figure 11 is a micrograph of the same steel, hydrogenated for four hours and degassed for seven days. This image is of the cracked region, showing that the crack depth is approximately $277 \mathrm{~nm}$, as the darker parts in the figures represent deeper regions in the structure, in this case the cracks, and the lighter parts represent slightly higher regions, demonstrating the the fact that the cracks detach part of the material in the form of a surface detachment. The depth of the pitch around $136 \mathrm{~nm}$ can be seen in the atomic force microscopy image in figure 12.

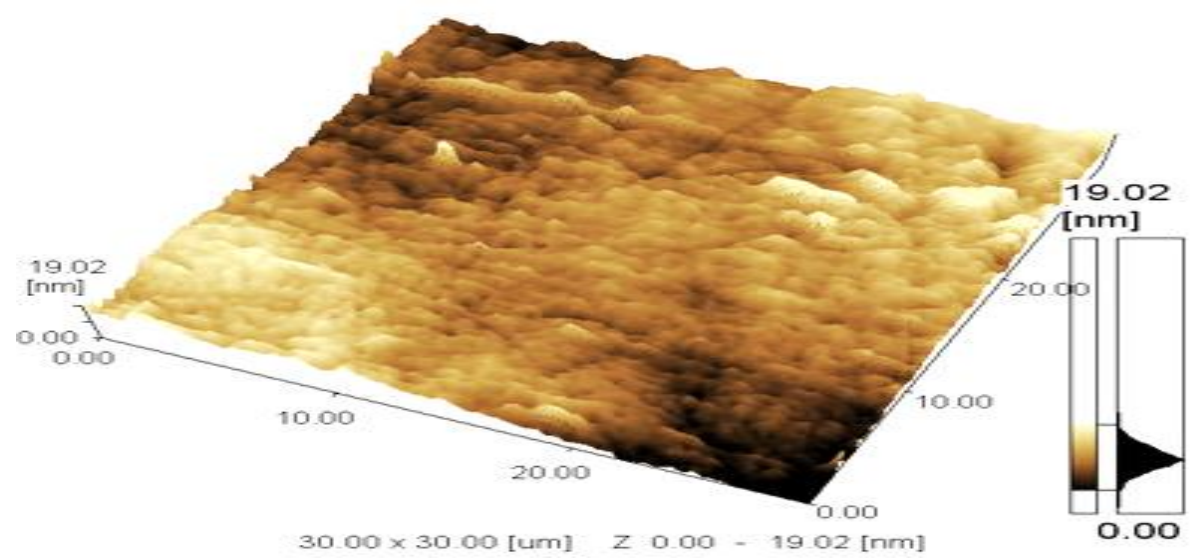

Figure 10: Depth profile in duplex stainless steel type SAF2101L without hydrogenation.

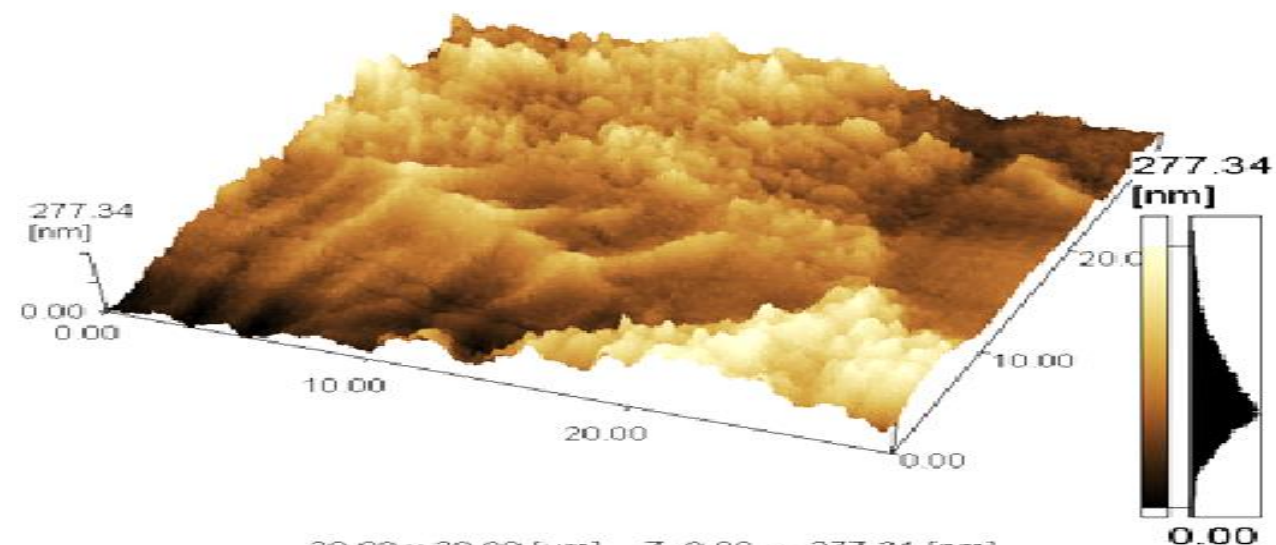

$3000 \times 3000[u m] \geq 0.00-277.34[\mathrm{~nm}]$

O. 00 


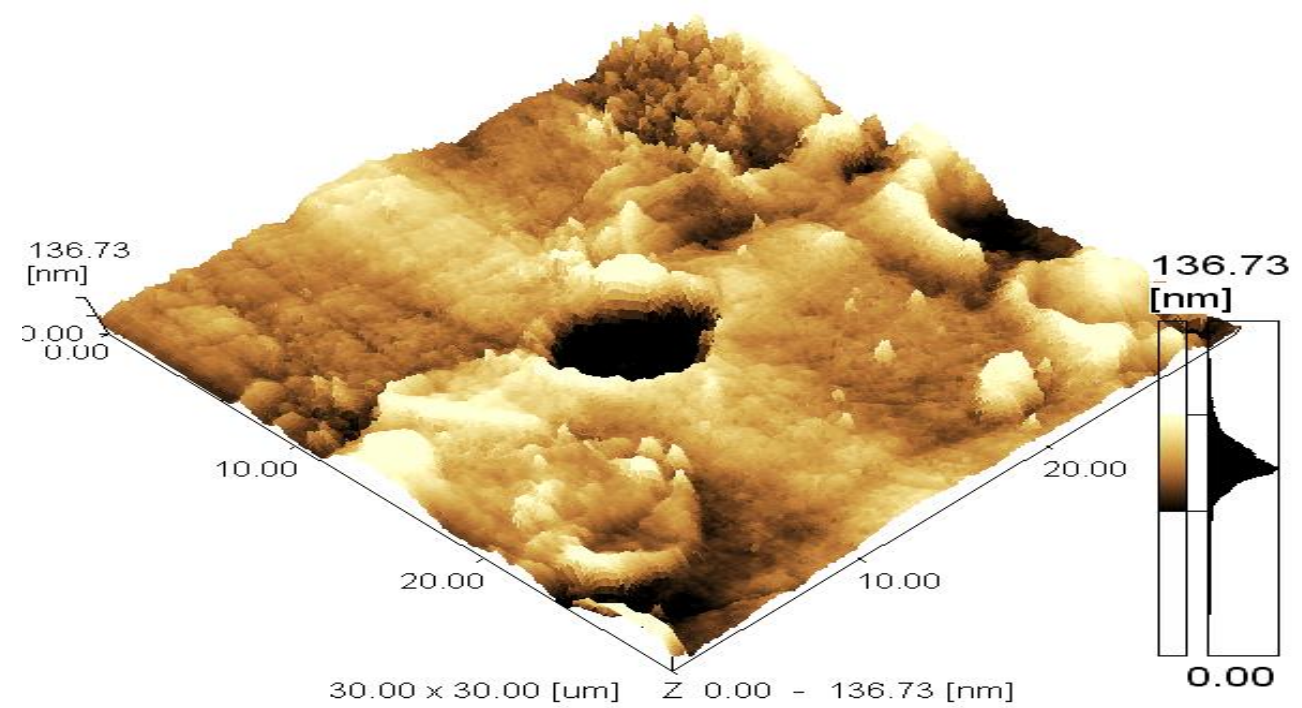

Figure 12: Pite depth profile in duplex stainless steel type SAF2101L hydrogenated for 4h and degassed for 7 days.

The phases and phase transformations, which occurred with the entry and exit of hydrogen in the material, were investigated by X-ray diffraction $[4,6,9,14,16]$. Once, in austenitic steels, degassing is an important part of this process [17]. In the samples of stainless steel of type UNS S32101 before hydrogenation, the phases $\square \square \mathrm{e} \square \square \square$ only were confirmed, as seen in graph (1). After hydrogenation, a diffractogram was performed after seven days of degassing, graph (2), showing dee $\square \square \square$ phase peaks as well as a peak at approximately $46.18{ }^{\circ}$. The transformation from $\square \square$ phase $\square^{\prime}$ (transformation from austenite to martensite: $\gamma \rightarrow \varepsilon \rightarrow \alpha^{\prime}$ ) was expected, due to the approximately $50 \%$ percentage of austenitic phase in the UNS S32101 duplex stainless steel $[4,6,14,18,19]$. Phase $\square$ is a stacking fault that arises during hydrogenation. Over time this phase $\square$ would turn into martensite $\square$ '. However, according to the literature, the $\square$ ' peak is approximately $45.95^{\circ}$ and the $\square$ peak is approximately $48^{\circ}$, which does not fit with the peak shown in the diffractograms of hydrogenated UNS S32101 duplex stainless steel samples, as this is at $46.18^{\circ}$. This peak coincides with the sigma phase peak $(\square)[20,21]$. The graph (3) is a comparison of graphs (1) and (2), that is, it is the UNS S32101 duplex stainless steel without hydrogenation and hydrogenated for 4h, and degassed for seven days, in this it is possible to see clearly the phase transformation of this steel after the entry and exit of hydrogen.

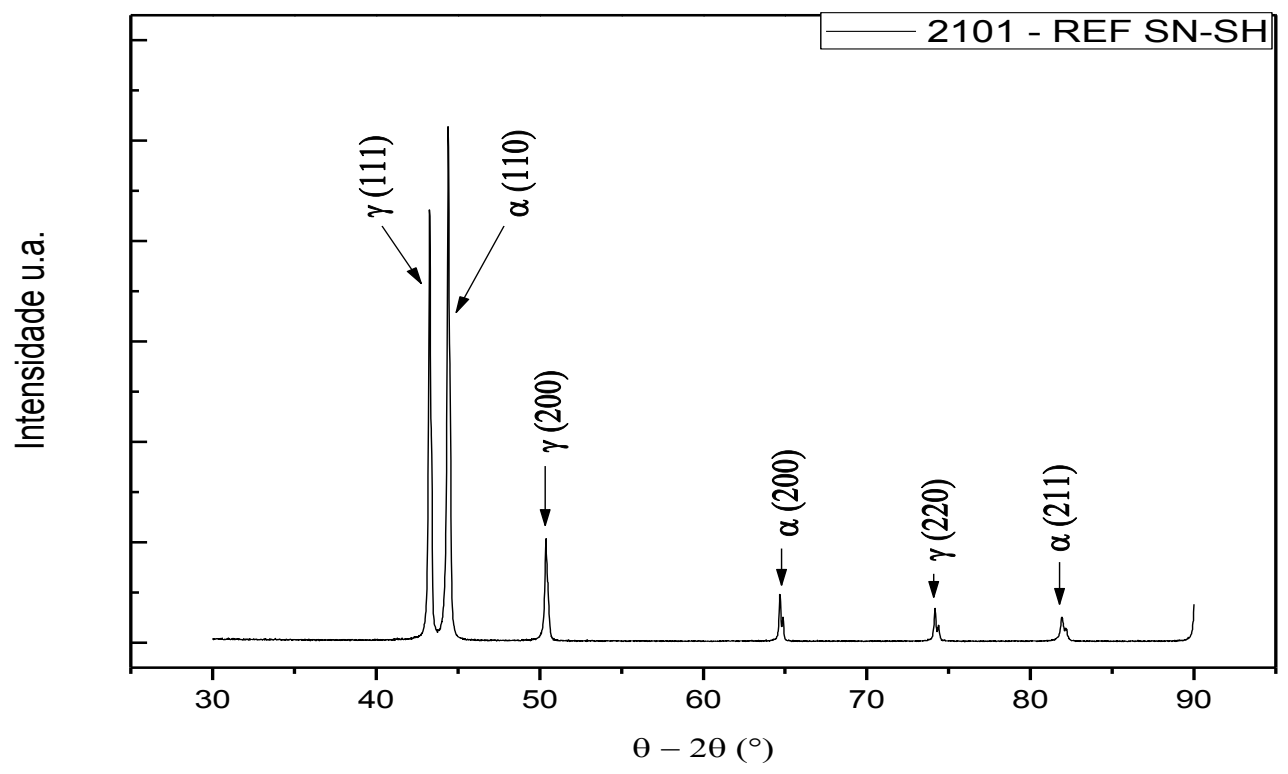


Graph (1) is the X-ray diffractogram of UNS S32101 duplex stainless steel without hydrogenation, showing the peaks of phases $\square$ and $\square$ present in the steel.

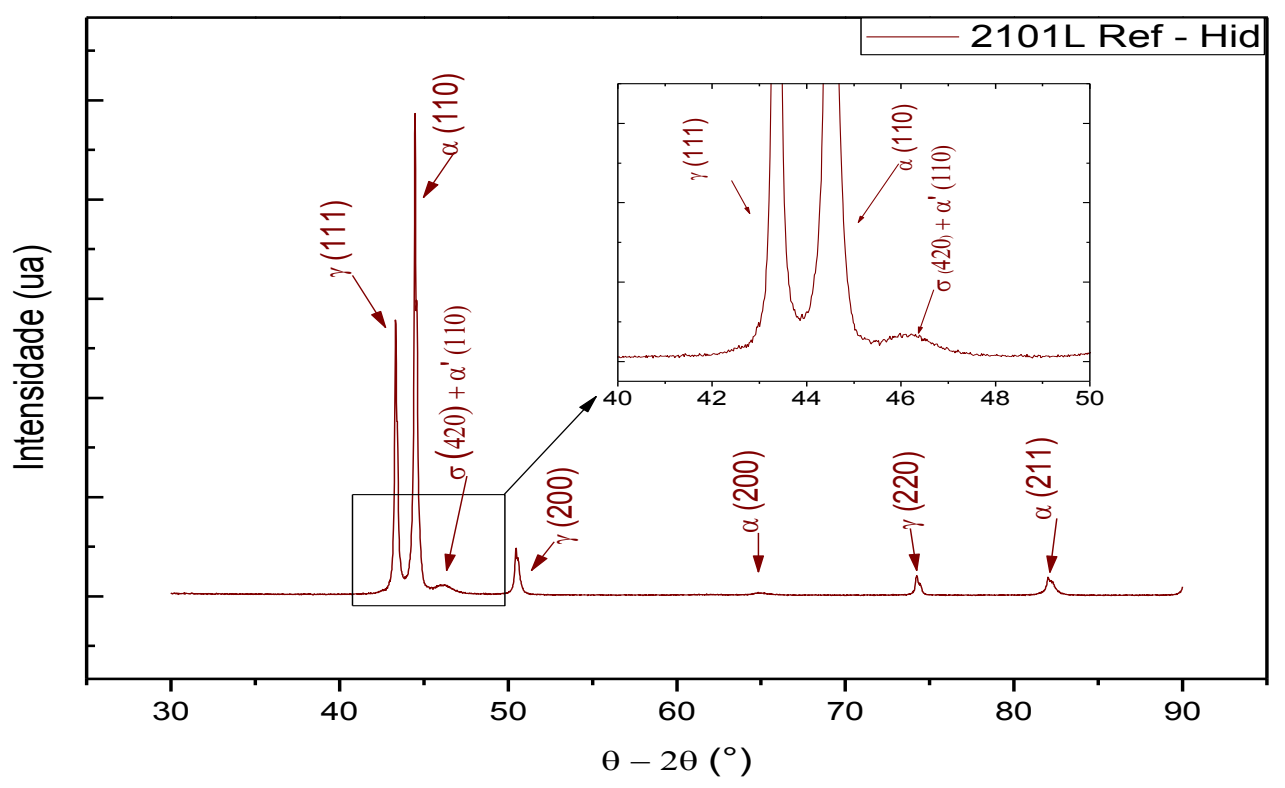

Graph (2) is the X-ray diffractogram of UNS S32101 duplex stainless steel, hydrogenated for 4h, after seven days of degassing, showing the peaks of phases $\square, \square$ and possibly $\square$ and $\square$ 'present in the steel.

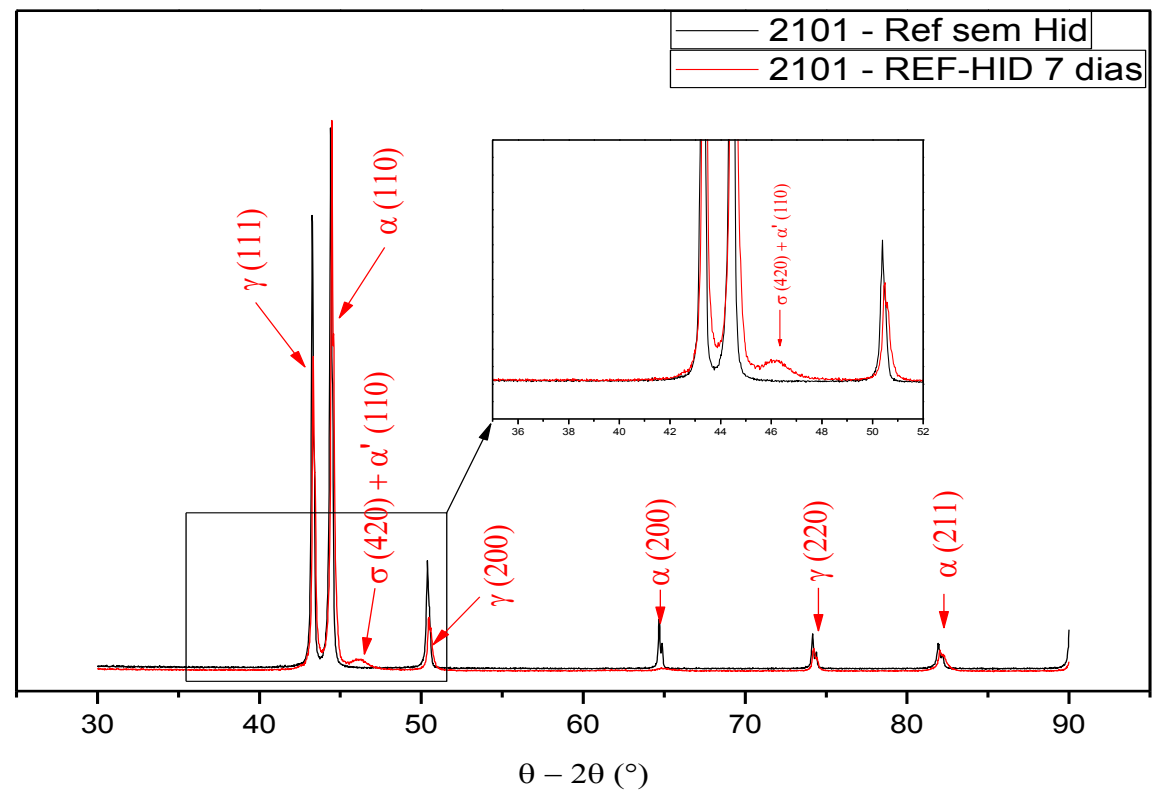

Graph (3) is the X-ray diffractogram of UNS S32101 duplex stainless steel without hydrogenation and hydrogenated for 4 hours, after seven days of degassing, showing the peaks of phases $\square, \square$ and possibly $\square$ and $\square$ ' present on steel.

Therefore, a more detailed analysis was necessary and thus, diffractograms of the kinetics of the hydrogen action in the phase transformation of the duplex stainless steel of the UNS S32101 type were made. In graph (4), the peaks of the phases present can be seen immediately after hydrogenation, that is, with 0h of degassing. In this graph, the peaks of the $\square \square$ and $\square \square \square \square$ phases are seen to be wider, probably due to the presence of hydrogen that did not detach from the material in time. Also noted is the presence of two new peaks, one at approximately $38^{\circ}$ and the other at $78^{\circ}$, which are identified as precipitates of the $\mathrm{Cr} 23 \mathrm{C} 6$ type [1]. According to Chen and Yang [21] this induces the formation of the $\square$-phase in the grain boundaries of the ferrite instead of the formation being in the grain boundaries of the austenite. The high rate of interfacial 
energy in $\square$ /M23C6 can contribute to the formation of the $\square$-phase. These authors state that the interfacial precipitation of the $\square$-phase in duplex stainless steel is supposed to stem from the inconsistency of the $\square / \square$ and $\square / \mathrm{M} 23 \mathrm{C} 6$ interfaces and, whereas, the $\square$-phase precipitation is inhibited at the $\square / \mathrm{M} 23 \mathrm{C} 6$ interfaces due to the coherence of the grain contours [22].

A new analysis was made after $24 \mathrm{~h}$ of degassing to verify the present phases, see graph (5). In this diffractogram it is noted that the peaks are no longer widened, possibly due to the evasion of hydrogen from the material, the peaks are still observed at $38^{\circ}$ and $78^{\circ}$, however with less intensity, since the peak that was before $46.18^{\circ}$ changes to approximately $45.97^{\circ}$. Thus, it can be understood that the material is in an unstable situation. However, looking at graph (6), when diffractometry is performed again with 7 days of degassing, the peak at $46.18^{\circ}$ is again noted and the peaks at $38^{\circ}$ and $78^{\circ}$ disappear, showing that the situation of instability ended.

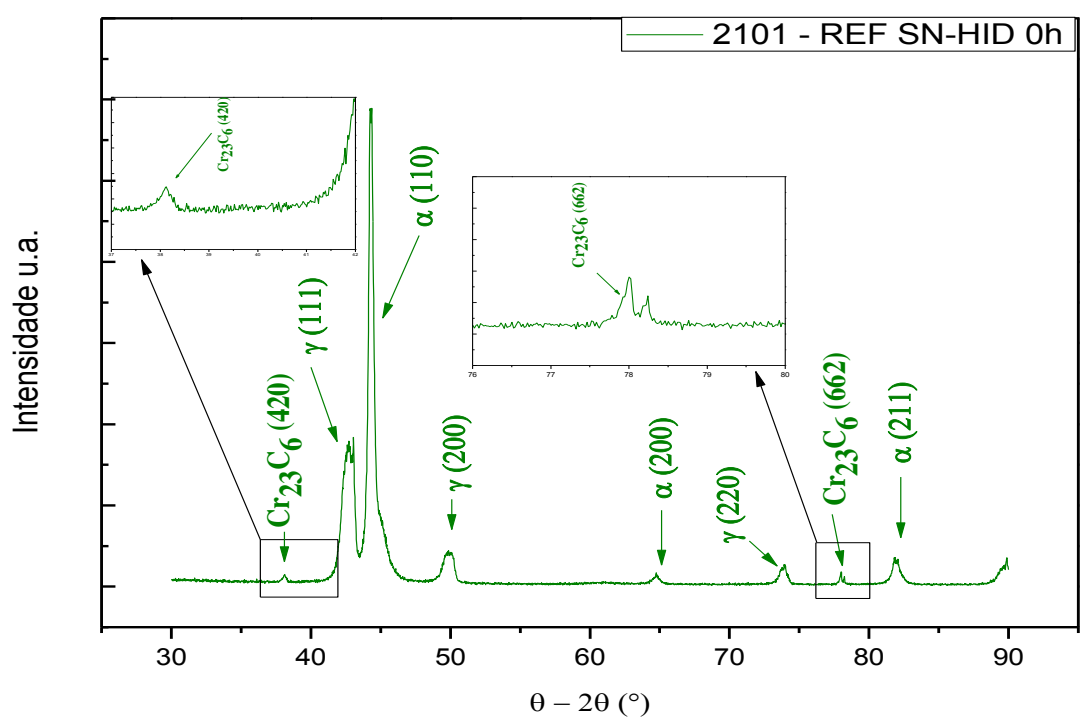

Graph (4) is the X-ray diffractogram of duplex stainless steel, type SAF2101, right after 4h hydrogenation (zero hours of degassing), showing the peaks of the phases present in the steel.

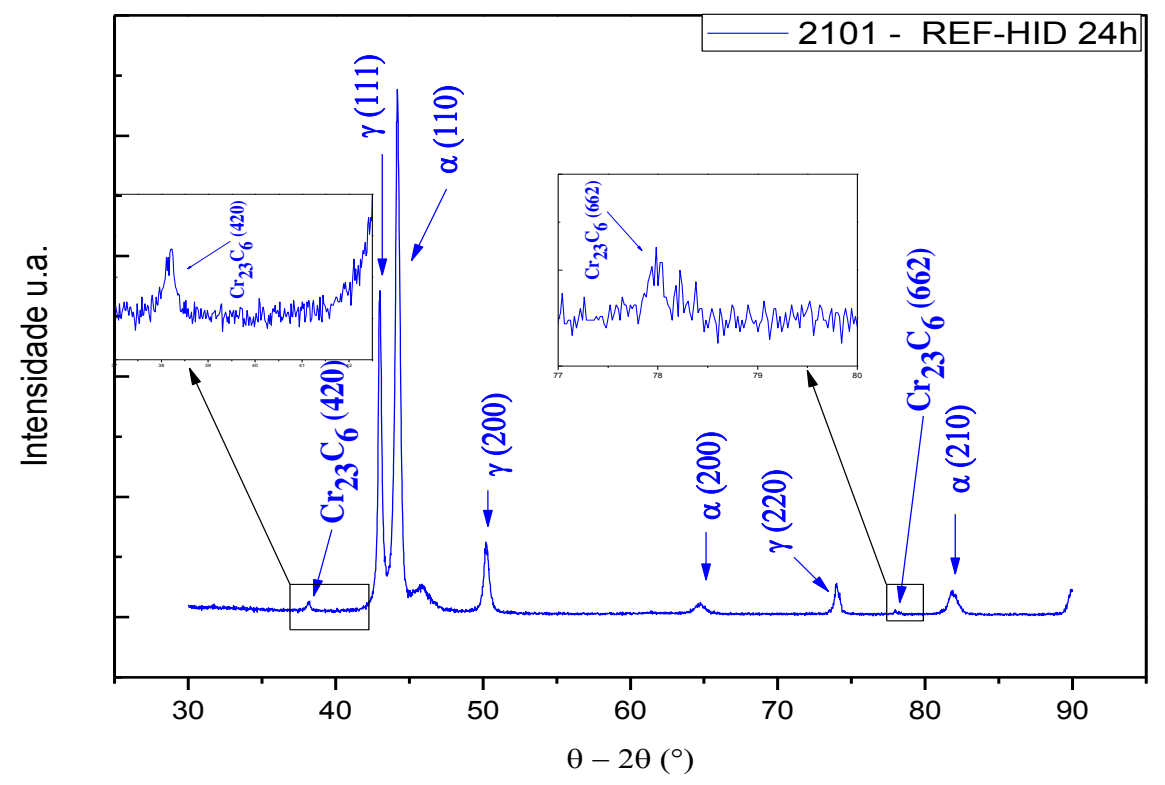

Graph (5) is the X-ray diffractogram of duplex stainless steel, type SAF2101, after 4h hydrogenation (twenty-four hours of degassing), showing the peaks of the phases present in the steel. 


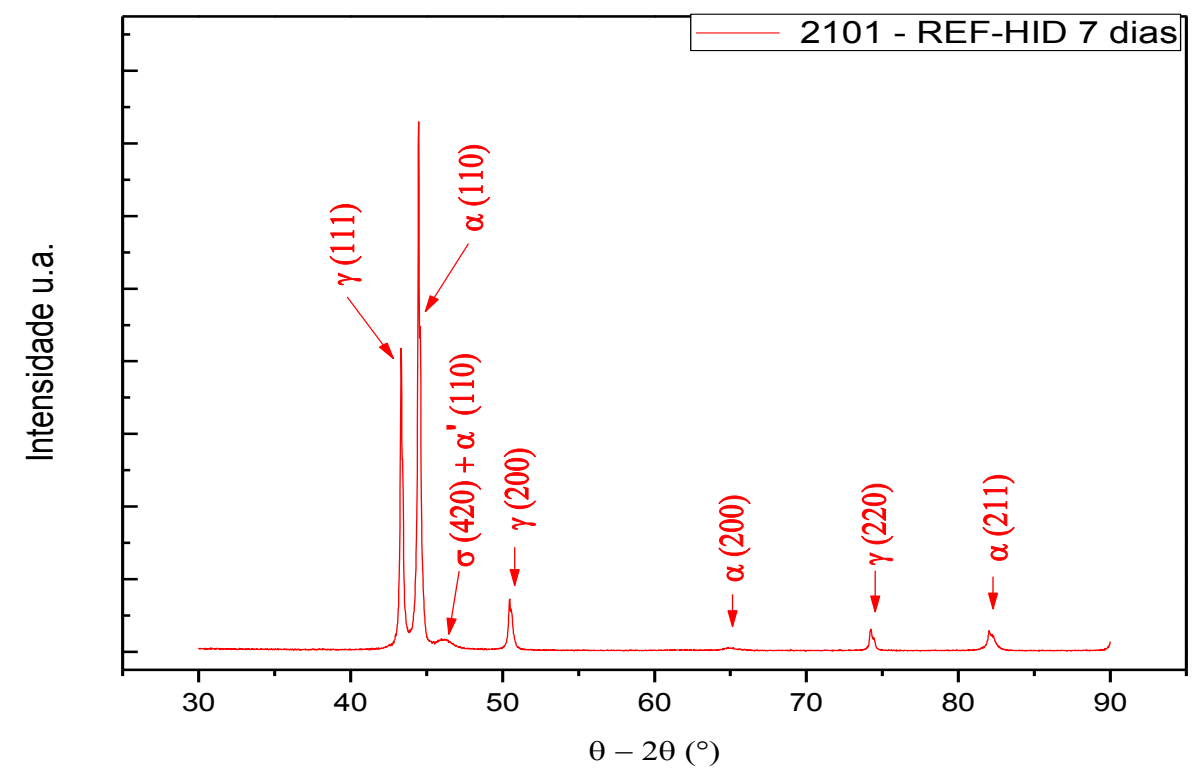

Graph (6) is the X-ray diffractogram of the duplex stainless steel type SAF2101, after hydrogenation for 4 hours (seven days of degassing), showing the peaks of the phases present in the steel.

The X-ray diffractograms of ferritic stainless steel of the AISI 430 type are shown in graph 7. In this, the

black curve shows the AISI 430 stainless steel only sanded, polished and without hydrogenation,

highlighting only the $\alpha$ ferrite peaks. The red curve is the X-ray diffractogram of the ferritic stainless steel

AISI 430 hydrogenated for $30 \mathrm{~min}$ and degassed for 7 days. In this it is possible to see the ferrite peaks $\alpha$ as well as two new peaks: one at approximately $38^{\circ}\left(38^{\circ} 12^{\prime}\right)$ and another close to $78^{\circ}\left(78^{\circ} 15^{\prime}\right)$. These peaks coincide with the peaks of Cr23C6 type precipitates identified by Mei and Guimarães [1].

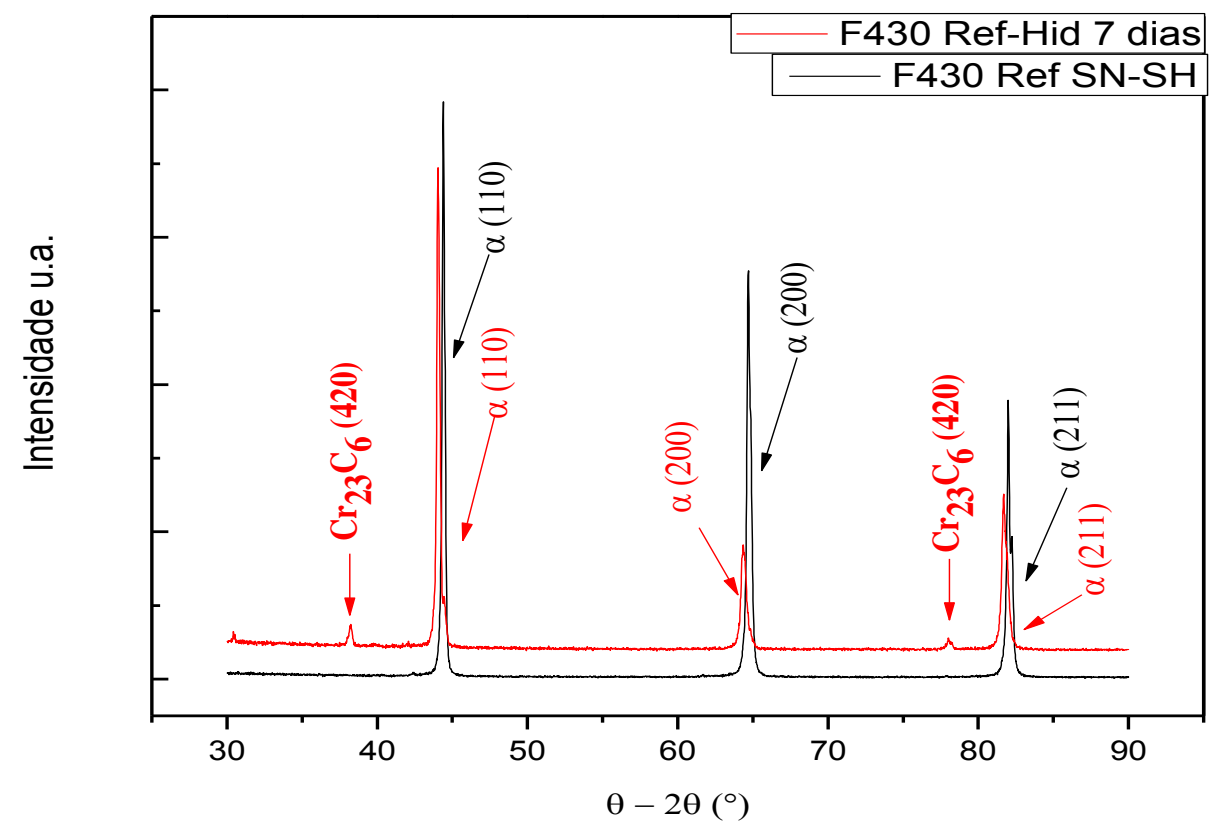

Graph 7: X-ray diffractogram of ferritic stainless steel of type AISI 430 without hydrogenation and hydrogenated for $30 \mathrm{~min}$, after seven days of degassing, showing the peaks of the phases present in the steel.

Chen and Yang [21] stated that the appearance of precipitates of the M23C6 type induces the formation of the $\sigma$-phase in duplex stainless steel. This is due to the interfacial inconsistency of these precipitates and the austenitic grains (M23C6/ $\square$ ), as in the $\alpha / \square$ interfaces when $\alpha$ is stressed with the formation of these 
precipitates, a theory confirmed by Porter, Easterling and Sherif [22]. Thus, it is possible to explain what happened in the duplex stainless steel type SAF2101 after cathodic hydrogenation.

It is known that hydrogen induces the formation of $\mathrm{Cr} 23 \mathrm{C} 6$ precipitates in the ferritic grains, these ferritic grains are inconsistent with the austenitic grains, but are highly stressed due to the precipitates that arose, in such a way that there is a high interfacial energy, sufficient for the formation phase $\sigma$. Padilha and Rios [23] guarantee that both carbon and nitrogen are insoluble in the $\sigma$-phase and, as a consequence, the $\sigma$-phase is precipitated commonly after the precipitation of carbides and/or nitrides, and the formation of this favors corrosion by pites. Therefore, explaining the localized corrosion that appears in figure 7 . It is clear that hydrogen induces the formation of precipitates of the Cr23C6 type.

Thus, as predicted, duplex stainless steel of the UNS S32101 type is susceptible to the deleterious effects of hydrogen. Therefore, it is stated that, during hydrogenation, that is, at the entrance of hydrogen, there is the formation of precipitates of the Cr23C6 type, and as a result there is an increase in tension between austenitic and ferritic grains with the formation of these precipitates. During degassing, these precipitates disappear due to the instability generated by hydrogen evasion. This implies a high interfacial energy, sufficient for the formation of the sigma phase at room temperature. As a consequence, pitting corrosion.

\section{Conclusions}

Finally, it was understood that hydrogen induces the formation of precipitates of type $\mathrm{Cr} 23 \mathrm{C} 6$ in ferritic stainless steel of type AISI 430 and which can induce the formation of the sigma phase ( $\square$ ) at room temperature in UNS S32101 duplex stainless steel, due to the formation of Cr23C6 precipitates in the ferritic grains during hydrogenation and, the high interfacial energy with their disappearance during degassing. Since this energy is sufficient for the formation of the sigma phase, and consequently, it explains the appearance of pitting corrosion, since this phase favors this type of corrosion.

\section{References}

[1.] MEI P.R., GUIMARÂES A. A. Precipitation of carbides and sigma phase in AISI type 446 stainless steel under working conditions. Journal of Materials Processing Technology, pp 155-156 (2004).

[2.] VERMA J., TAIWADE R. V., KHATIRKAR R. K., KUMAR A. A Comparative Study on the Effect of Electrode on Microstructure and Mechanical Properties of Dissimilar Welds of 2205 Austeno-Ferritic and 316L Austenitic Stainless Steel. Materials Transactions, vol. 57, pp 494 500, (2016).

[3.] MANOVA, D., MÄNDL, S. Nitrogen Transport in Expanded Austenite Formed in Stainless Steels and $\mathrm{CoCr}$ Base Alloys. Materials Performance and Characterization, vol. 6, No. 4, pp 617-641, ,(2017).

[4.] GAVRILJUK V.G., MOGILNY G.S., TEUS S.M., SHYVANYUK V.N. Plastic deformation and phase transformations in austenitic steels in the course of hydrogen charging and subsequent mechanical tests. Materials Science and Engineering A, vol. 648, pp 260-264, (2015).

[5.] YANG J., ZHENG W., HE Y., GAO Z. Hydrogen diffusion mechanism of the single-pass welded joint in welding considering the phase transformation effects. Journal of Manufacturing Processes, vol. 36, pp 126-137, (2018).

[6.] CARTER, T. S.; CORNISH, L. A.; Hydrogen in Metals, Engineering Failure Analysis, vol. 8, p. 113-121, (2001).

[7.] MATSUOKA S., YAMABE, J., MATSUNAGA, H. Hydrogen-Induced Ductility Loss of Austenitic Stainless Steels for Slow Strain Rate Tensile Testing in High-Pressure Hydrogen Gas. Solid State Phenomena, vol. 258, pp. 259-264, (2017).

[8.] RAO G. S., SEIFERT H. P., RITTER S., SPÄTIG P., QUE Z. Effect of hydrogen on tensile behavior of low alloy steel in the regime of dynamic strain ageing. Procedia Structural Integrity, vol. 2, pp 3399-3406, (2016).

[9.] HARDIE D.,CHARLES E.A.,.LOPEZ A.H. Hydrogen embrittlement of high strength pipeline steels. Corrosion Science, vol. 48, Issue 12, pages 4378-4385, (2006).

[10.] KOYAMA M., AKIYAMA E., LEE Y. K., RAABE D., TSUZAKI K., Overview of hydrogen embrittlement in high-Mn steels, Int. J. Hydrog. Energy 42 (17) (2017) 12706-12723. 
[11.] ZINBI , A. , BOUCHOU, A., Delayed cracking in 301 austenitic steel after bending process: Martensitic transformation and hydrogen embrittlement analysis, Engineering Failure Analysis (2009).

[12.] ALYOUSIF, O. M.; NISHIMURA, R., A hydrogen embrittlement mechanism for sensitized types 304, 316 and 310 austenitic stainless steels in boiling saturated magnesium chloride solutions, Corrosion Science 52, p. 7-13 (2010).

[13.] MICHLER, T.; NAUMANN, J., Hydrogen environment embrittlement of austenitic stainless steels at low temperatures, International Journal of Hydrogen Energy 33, p. 2111 - 2122 ( 2008 ).

[14.] BUGAEV V. N., GAVRILJUK V. G., PETROV Y. U. N. AND TARASENKO A V., Mechanism of Hydrogen- Induced Phase Transformations in Metals and Alloys, Int. J. Hydrogen Energy, vol. 22, No 2/3, pp 213-218 (1997).

[15.] TEUS, S.M., SHYVANYUK, V.N., GAVRILJUK V.G., Hydrogen-Induced $\square \rightarrow \square$ transformation and the role of $\square$-martensite in hydrogen embrittlement of austenitic steels, Materials Science and Engineering A 497, p. 290-294 (2008).

[16.] SILVA T. C. V., PASCUAL R. E MIRANDA P. E. V., Hydrogen Induced Surface Effects on the Mechanical Properties of type 304 Stainless Steel, Fracture Prevention in Energy and Transport Systems, Eds. I. Lemay and S. N. Monteiro, EMAS, London, pp 511-520 (dez/1984).

[17.] KUROMOTO N. K., FIUSA D. L., CANTÃO M. P., LEPIENSKI C. M., Nanoscratching Characterization of Austenitic Stainless Steel Modified by Cathodic Hydrogenation, Materials Science and Engineering A 269 pp 83-89 (1999).

[18.] HERMIDA J. D., ROVIGLIONE A, Stacking Fault Energy decrease in Austenitic Stainless Steels Induced by Hydrogen Pairs Formation, Scripta Materialia, vol.39, nº, pp 1145-1149 (1998).

[19.] GAVRILJUK V. G., TARASENKO A V. AND TERESHCHENKO A S., Phase Transformations and Relaxation Phenomena Induced by Hydrogen Stainless Steels, Int. J. Hydrogen Energy, vol. 22, No 2/3, pp 269-277 (1997).

[20.] GAO J., JIANG Y., DENG B., ZHANG W., ZHONG C., LI J., Investigation of selective corrosion resistance of aged lesn duplex stainless steel 2101 by non-destructive electrochemical techniques, Electrochimica Acta 54, pp 5830-5835 (2009).

[21.] CHEN T. H., YANG J. R., Effects of solution treatment and continuous cooling on $\sigma$-phase precipitation in a 2205 duplex stainless steel, Materials Science and Engineering A 311, pp 28-41 (2001).

[22.] PORTER D. A., EASTERLING K. E., SHERIF M. Y., Phase Transformations in Metals and Alloys, $3^{\text {a }}$ edição, pp 150-157 (2009).

[23.] PADILHA, A.F.; RIOS, P.R. Decomposition of Austenite in Austenite Stainless Steels. ISIJ Internacional, 42, pp 325-337(2002). 